\title{
Viajar e textualizar as memórias do medievo*
}

\author{
Susani Silveira Lemos França \\ Universidade Estadual de São Paulo - Franca
}

\begin{abstract}
$\sim 7$
relação entre a memória e a vida espiritual é um dos tópicos incontornáveis para aqueles que se dispõem a refletir sobre a história das ideias no medievo e sobre as formas como os homens de então construíram e fixaram suas verdades. Tais verdades, como não poderia deixar de ser em uma época profundamente religiosa, eram entendidas como uma espécie de recordação das verdades eternas e, por isso mesmo, como veremos adiante, tais recordações, quando eram textualizadas na forma de relatos de viagem, ora visavam retomar os passos de Cristo na Terra Santa, com a finalidade de imprimir nos espíritos "a lembrança da sua Paixão", ${ }^{1}$ ora oscilavam entre extremos negativos ou positivos, especialmente quando se avançava por territórios menos conhecidos, como o do "povo horrível e monstruoso dos Tártaros".2

A singularidade da recordação das verdades eternas, nessas narrativas, mostra-se ligada ao fato de recordarem aquilo que dizia respeito a um passado que reforçava a sua fé - a sequência dos passos de Cristo, caminho certo para o céu $-^{3}$ ou,
\end{abstract}

\footnotetext{
* Todas as fontes em outras línguas são traduções minhas.

${ }^{1}$ MONTE CROCE, 1997, p. 39.

${ }^{2}$ MONTE CROCE, 1997, p. 79.

${ }^{3}$ SIGAL, 1974, p. 8.
} 
em contraponto, ao fato de recordarem ritos, costumes, feições de povos que não lhes diziam diretamente respeito - apesar de, ao falarem dos outros, dizerem igualmente de si mesmos. É essa segunda forma de lembrança que examinaremos aqui mais detidamente a partir dos relatos de viagem à Terra Santa e a outras regiões orientais escritos por viajantes cristãos dos séculos XIII, XIV e XV. Cabe-nos examinar que tipo de textualização da memória é proposto nos relatos de viagem desses séculos, já que tal projeção se dá dentro de um conjunto de valores e expectativas sobre o que merecia ser lembrado e fixado pela escrita.

Em 1288, o dominicano Riccoldo de Monte Croce, de Florença, aventurou-se pelo coração do mundo muçulmano, Bagdá, acerca do qual registrou suas lembranças e o que lá pôde aprender; um registro, a Peregrinatio, sempre conduzido por seus objetivos missionários e que se pretende um manual para os frades futuramente incumbidos de catequizar o Oriente. ${ }^{4} \mathrm{No}$ seu relato, entretanto, chamam atenção as justificativas iniciais de que escreve para que os frades que fossem, depois dele, "difundir a fé, soubessem aquilo de que teriam necessidades, bem como onde e de que maneira eles poderiam ter êxito". 5 Tal comprometimento de ensinar seus congêneres sobre como agir nãoé, porém, o alvo mais comum desses viajantes comprometidos em articular experiência alheia e passada, a de viajantes anteriores ou eruditos que eram referência na Idade Média (Vincent de Beauvais, Guilherme Boldensele, Jacobo de Varazze, Brunetto Latini, Marco Polo, Odorico de Pordenone, etc.), com experiência própria e recente, a do viajante que observa os lugares por onde passa e as gentes que visita. $\mathrm{O}$ próprio Monte Croce, aliás, declara que pretende olhar para todos "os reinos, os povos, as províncias, as leis, os ritos, as

${ }^{4}$ KAPPLER, 1997, p. 10.

${ }^{5}$ MONTE CROCE, 1997, p. 37. 
seitas, as heresias e os monstros" que podiam ser achados nas cercanias das terras conhecidas do ocidente. ${ }^{6}$

Olhá-los para quê, se pareciam uma gente perdida? Em um trecho do Sermão sobre o conhecimento e a ignorância, Bernardo de Claraval, por exemplo, distingue os saberes benéficos, aqueles que conduzem à salvação, ${ }^{7}$ dos saberes sem sobriedade, que estão para além "do que convém". ${ }^{8}$ O que entre os séculos XIII e XV era entendido como saber que convém não era certamente consensual, mas o que os viajantes começaram a pensar que caberia ser dado a conhecer tinha, sem dúvida, uma forma mais regular. Julgaram, por exemplo, que, ao lado do passado glorioso cristão, os vícios dos povos ainda não cristianizados poderiam servir para fazer lembrar que o caminho traçado para os cristãos era o melhor caminho, por isso justificaram que convinha registrar o que por lá tinham contemplado, como faz João de Pian del Carpine, ao se comprometer a levar "conhecimento" aos "fiéis de Cristo". 9

O próprio desejo de conhecer uma verdade, de acordo com um dos pensadores cuja obra é tomada como uma síntese das mais bem sucedidas da antropologia medieval, ${ }^{10}$ Tomás de Aquino, poderia ser condenável se seu uso não fosse moralmente virtuoso. Esse uso desvirtuoso poderia ocorrer de quatro maneiras principais: "quando, por um estudo menos útil, alguém desleixa outro ao qual deveria se aplicar, por obrigação"; em segundo lugar, "quando alguém procura aprender de quem não se deve, como os que vão interrogar os demônios para

${ }^{6}$ MONTE CROCE, 1997, p. 37.

7 CLARAVAL, 1998, p. 263.

8 CLARAVAL, 1998, p. 264-265.

9 JOÃO DE PIAN DEL CARPINE, 2005, p. 27.

${ }^{10} \mathrm{VAZ}, 1991$, p. 68 e 69. 
conhecer o futuro, o que é curiosidade supersticiosa"; "quando o homem deseja conhecer a verdade sobre as criaturas, sem se reportar ao fim devido, ou seja, ao conhecimento de Deus"; e, por fim, "quando alguém ambiciona conhecer uma verdade superior às suas possibilidades, pois assim cai, facilmente, em erros" ${ }^{11}$ O célebre dominicano concebe, nesse sentido, uma hierarquia de utilidades e verdades, sendo consideradas repreensíveis aquelas que não se ordenam "ao conhecimento da suma verdade, na qual se acha a suma felicidade. ${ }^{12}$

O referido Riccoldo de Monte Croce, por exemplo, parecia se interessar pelos povos do oriente por representarem a antítese de todos os valores cristãos, tendo sido enviados pelo Senhor Deus às terras do oriente "para matar e destruir", enquanto para o ocidente tinham sido enviados com missão muito mais engrandecedora Domingos e Francisco, incumbidos de "aclarar, instruir e edificar". ${ }^{13}$ Ainda assim, mesmo que ele visse uma trajetória proporcionalmente oposta, em que ao "sucesso na edificação", de um lado, correspondia a supremacia "na destruição", de outro, alguns dos seus contemporâneos não descartaram que a sua missão era vencer as barreiras da desedificação e buscar converter os idólatras. João de Montecorvino, por exemplo, ainda no final do século XIII, conta que batizou "cerca de seis mil pessoas", e teria feito melhor não fossem as difamações de que foi vítima e não fosse estar sozinho nessa missão. Teria mesmo podido converter o Grande Cã se estivesse acompanhado, e por isso pedia que outros frades fossem enviados àquelas terras. ${ }^{14}$

\footnotetext{
${ }^{11}$ TOMÁS DE AQUINO, 2002, questão 167, artigo 1, p. 450-451.

12 TOMÁS DE AQUINO, 2002, questão 167, artigo 1, p. 451.

${ }^{13}$ MONTE CROCE, 1997, p. 95.

${ }^{14}$ JOÃO DE MONTECORVINO, 2005, p. 259-260.
} 
Como Montecorvino, outro franciscano, Odorico de Pordenone, do século posterior, igualmente narra experiências dos frades menores que são indicativas de que havia esperança de se levar a verdadeira fé aos tártaros, ${ }^{15}$ tal como viria a propor um outro frade dominicano do século XIV, Jordan Catala de Sévérac, que seria possível fazer com os povos da Índia. Jourdain, convicto da superioridade da Cristandade, propunha que, "se houvesse duzentos ou trezentos bons frades que quisessem com fé e fervor pregar a fé católica, não haveria sequer um ano sem que mais de dez mil pessoas se convertessem à nossa verdadeira fé". ${ }^{16}$ Acreditaram, pois, que deviam registrar tudo aquilo que encorajasse os seus a persistirem no caminho da expansão da fé católica em terras de infiéis. Como esses, outros viajantes coetâneos quiseram textualizar suas memórias, empenhados em estimular que outros, como eles, seguissem seus passos na conversão dos infiéis das várias partes de lá. Imbuídos, de forma difusa, das ideias de Aristóteles sobre o papel da memória na apreensão do mundo sensível ou melhor, sobre a possibilidade de que o mundo material pudesse ser conhecido, mas havendo um lapso de tempo entre a experiência e a sua recordação"17 -, esses viajantes narraram

${ }^{15}$ ODORICO DE PORDENONE, 2005, p. 334.

${ }^{16}$ CATALA SÉVÉRAC, 2005, p. 294.

${ }^{17}$ Segundo Janet Coleman, para Platão, os objetos do pensamento não estão alojados na memória como estão para Aristóteles; as formas existem separadas do sensível, material, mundo corporal. Mas Aristóteles acredita que poucas coisas podem existir separadamente do mundo sensível e o pensamento sensível exige que os veículos a que ele se refere como formas sensíveis das coisas externas sejam de alguma forma transferidos para o órgão sensorial que percebe, sendo as formas sensíveis e as imagens da memória semelhantes ao verdadeiro. COLEMAN, 1992, p. 16-17. 
suas experiências de modo a fazer das suas lembranças ao mesmo tempo um instrumento para estimular seus congêneres a trabalhar para expandir seus valores nessas terras e o espelho das terras do lado de lá.

Nesses três séculos em questão, vale ainda destacar, o sentido religioso das recordações da peregrinação, em que o caminho percorrido se confunde com o da salvação eterna, ${ }^{18} \mathrm{e}$ o sentido missionário das recordações, em que sobressai o comprometimento de converter, vem se juntar a ambição por conhecer as diversidades e estranhezas do mundo em parte desconhecido. As formas dadas a esse mundo desconhecido, apesar da frequente afirmação do testemunho por vista ou de ouvir falar de pessoas fidedignas, como faz Carpine, ${ }^{19}$ eram conduzidas por parâmetros, como foi referido anteriormente, relativamente fixos, ou melhor, estabelecidos com certa regularidade. Dado que as descrições dos lugares e povos são muitas vezes vagas, apressadas e feitas por viajantes em sua maioria de passagem, tal regularidade não se sustenta em uma observação mais demorada, já que poucos ficam mais do que 5 anos e muitos ficam bem menos que isto. ${ }^{20}$ Portanto, tais registros não escondem o apego dos viajantes aos seus préjulgamentos, ou seja, a persistência de referentes culturais de longa data, que pesam mais do que o impacto da observação direta, diferentemente, por exemplo, do que acontecerá com os viajantes do século XVI, que fazem da experiência a "pedra de toque da verdade", e enfraquecem o peso da autoridade na sustentação da sua observação do mundo. ${ }^{21}$

${ }^{18}$ WOLFZETTEL, 1996, p. 10-11.

${ }^{19}$ JOÃO DE PIAN DEL CARPINE, 2005, p. 30.

${ }^{20}$ Daí que seus livros possam ser vistos como livros de impressão. CHAREYRON, 2004, p. 24.

${ }^{21}$ HOOYKAAS, 1983, p. 37. 
A despeito, porém, de dizerem do que viram ou do que esperavam ver, é essa outra função de textualização das recordações, isto é, de dar a conhecer a diversidade do mundo - como diz o viajante que ficou no oriente entre 1336 e 1341 e deixou uma espécie de apanhado sobre os países do Mediterrâneo e do Próximo Oriente, Ludholf Sudhein -, que vai se impondo nos relatos desse tempo. Ludolph, a esse propósito, abre seu relato explicando que, tendo viajado para o além-mar por cinco anos, desejou escrever "para o prazer do leitor" aquilo que viu "nas cidades, castelos, lugares de oração", e acrescenta, bem como aquilo que sabia "dos habitantes, seus costumes e as maravilhas que podem divisar aqueles que atravessam o mar". ${ }^{22}$

Se o viajante de Sudhein anuncia como costumes e maravilhas o que tinha a contar, o franciscano Odorico de Pordenone, como o viajante alemão, define o que narraria como "coisas grandes e maravilhosas" ${ }^{23}$ Coisas tão estranhas que não teve coragem de referir todas elas, dada a sua incredibilidade para os que não tivessem visto por si. ${ }^{24}$ Não falando em maravilhas, mas em "algumas coisas desconhecidas" nas terras cristãs, o célebre viajante do século anterior, o franciscano João de Pian del Carpine, querendo ser útil "aos cristãos", compromete-se em escrever-lhes, mesmo sob o risco de ser considerado mentiroso, acerca daquilo que tinha apurado com os "próprios olhos" ou de ouvir de cristãos "dignos de fé" que estavam nas regiões de além-mar. ${ }^{25}$ No seu compromisso de orientação aos cristãos, segundo o cronista Frei Salimbene de Parma, "os costumes dos Tártaros e outras maravilhas do

${ }^{22}$ SUDHEIN, 1997, p. 1032.

${ }^{23}$ ODORICO PORDENONE, 2005, p. 283.

${ }^{24}$ ODORICO PORDENONE, 2005, p. 336

${ }^{25}$ JOÃO DE PIAN DEL CARPINE, 2005, p. 29-30. 
mundo estavam incluídas", sem dúvida. ${ }^{26}$ Outro célebre franciscano, Guilherme de Rubruc, comprometido em registrar "tudo" o que visse para o rei Luís IX dos francos, anuncia que descreveria, de acordo com suas capacidades, os tártaros, "a sua vida e os seus costumes" ${ }^{27}$ E o referido Frei João de Montecorvino vincula o visto nas terras do oriente a uma forma privilegiada de conhecer, o conhecer do que ainda não se sabe. Escreve ele aos seus irmãos franciscanos, Frei Bartolomeu de São Concórdio e Frei Mentilo de Espoleto, que contaria "certas coisas", porque sabia que tinham "grande zelo pela ciência" e queriam "ter sabedoria e conhecimento de todas as coisas". ${ }^{28}$ Estava, assim, coadunado com um tipo de realismo em desenvolvimento no seu tempo, inspirado na idéia de que este mundo é o ponto de apoio necessário para aquele que quer se elevar ao plano superior, o reino de Deus. ${ }^{29}$

Missionários e outros viajantes registraram suas recordações com a finalidade declarada de destacar "maravilhas" e "coisas notáveis" para atrair aqueles que desejavam ver as faces do mundo, como sugere o dominicano Jourdain Cathala de Sévérac no século XIV. ${ }^{30}$ No que diz respeito aos peregrinos, pode-se notar que um certo conjunto de possibilidades para se pensar a devoção ambulante aparece consolidado e permite notar como a narração das viagens piedosas conduz-se por um

${ }^{26}$ JOÃO DE PIAN DEL CARPINE, 2005, p. 27.
${ }^{27}$ GUILHERME DE RUBRUC, 2005, p. 115 e 120.
${ }^{28}$ JOÃO DE MONTECORVINO, 2005, p. 253.

${ }^{29}$ Étienne Gilson explica que o realismo medieval, ainda que herdeiro do aristotélico, se distancia dele por colocar em dúvida o idealismo platônico não em prol de uma ciência voltada para o reino do homem, mas por proporem que o reino de Deus não é deste mundo, apenas tem nele seu apoio. Cf. GILSON, 1989, p. 245.

${ }^{30}$ CATALA SÉVÉRAC, 2005, p. 271. 
conjunto de tópicos, ou melhor, por um certo jogo vocabular com relativa monotonia. Nesse cenário, o conteúdo da observação e a carga cultural do narrador partilham igual espaço, tornando inteiramente indistintas as experiências vividas e as lidas. A técnica e o arcabouço literários conduzem, pois, o registro da trajetória peregrina, pondo em cena contextos e textos de épocas diversas.

A falta de originalidade pode ser notada nos diversos tipos de relato ${ }^{31}$ que circundam as experiências desses letrados peregrinos atentos às curiosidades da paisagem do caminho de Jerusalém, preocupados em afirmar, reafirmar e não perder de vista o seu objetivo religioso e, por fim, reverentes aos relatos dos seus antecessores. Tanto frades, como Symon Semeonis, do convento irlandês de Clonmel (viajou para Jerusalém na primavera de 1323 junto com o monge Hugues 1'Enlumineur), quanto enviados em missões de reconhecimento da Terra Santa, como o borgonhês Bertrand de La Broquière, quanto cronistas, como Guillaume de Tyr e Robert de Clari ${ }^{32}$ - um pouco antes -, ou ainda aventureiros peregrinos, todos eles participaram de um jogo cujas peças combinaram referências literárias e experiência religiosa particular.

Além do supostamente "falso" viajante, mas verdadeiro narrador Jean de Mandeville, merecem ser lembrados Ogier d'Anglure, Nompar de Caumont e Ghillebert de Lannoy. Mandeville diz ter viajado em 1322, o relato do francês Ogier d'Anglure é de 1395, 33 o do gascão Nompar de Caumont de 1417, o do borgonhês Ghillebert de Lannoy, de $1421 .{ }^{34}$ Mandeville, ainda

${ }^{31}$ Muitas vezes é difícil distinguir os limites entre uma peregrinação e uma embaixada. ZUMTHOR, 1993, p. 288.

32 RÉGNIER-BOHLER, 1997, p. XII.

33 OGIER D'ANGLURE, 1878, p. 32.

${ }^{34}$ SIGAL, 1974, p. 98. 
que provável viajante imaginário, encaixa-se no perfil desses peregrinos dos séculos XIV e XV, os peregrinos pós-cruzadas, como nota Nicole Chareyron, peregrinos "espiritualmente modelados pelo patrimônio da memória coletiva" e "munidos de sua cultura histórica e das ficções do seu imaginário" ${ }^{35} \mathrm{O}$ interesse histórico da sua compilação e dos relatos desses cavaleiros aventurosos está em um certo desapego espiritual aos lugares santos, ${ }^{36}$ ou melhor, está na atribuição de igual peso a esses lugares e ao pitoresco do caminho, bem como às estranhezas dos arredores da Terra Santa. Mesmo que Mandeville afirme sua devoção em um prólogo de elogio a Jerusalém e Jesus, conclamando os cristãos a "um tal Senhor amar e honrar, temer e servir, e essa santa terra honrar e exaltar, pois nos proporcionou o fruto pelo qual todo homem pode ser salvo",, 37 são claros, ao longo da narrativa, os desvios dos propósitos anunciados para a viagem. Tais desvios anunciam-se na própria divisão do livro em duas partes, em que a segunda dilui o universo piedoso e exacerba o maravilhoso que caracterizou muitos relatos de viagem anteriores à grande expansão para a América. Mandeville anuncia, logo na abertura do capítulo XVI, que, como já tinha falado da "Terra Santa, das terras circundantes e dos muitos caminhos que há para se chegar até lá", falaria agora "de outros lugares, ilhas, animais e povos que estão mais além". ${ }^{38}$ Entram em cena os territórios situados a leste da Palestina, incluindo terras da Índia, da China e das ilhas do Extremo Oriente.

Partilhando as ficções realistas de Mandeville, os cavaleiros Ogier d'Anglure, Nompar de Caumont e Ghillebert de Lannoy

${ }^{35}$ CHAREYRON, 2000, p. 15.
${ }^{36}$ GRABOÏS, 1998, p. 153.
${ }^{37}$ JEAN DE MANDEVILLE, 2007, p. 34.
${ }^{38}$ JEAN DE MANDEVILLE, 2007, p. 145. 
organizam suas narrativas em função das etapas do itinerário percorrido $^{39}$ e, especialmente no caso do último, o intuito explorador ameniza as nuances religiosas. ${ }^{40}$ Mas ainda assim grande parte do seu itinerário é centrado em Jerusalém e arredores, anunciados de saída como meta da viagem. Se, pois, Mandeville apresenta Jerusalém como o "centro do mundo" e onde Jesus se sacrificou por nós, Nompar de Caumont declara que saiu para o "ultramar" para chegar ao Santo Sepulcro, onde Jesus sofreu a paixão e morreu. ${ }^{41}$ Do mesmo modo, os outros dois viajantes descrevem suas trajetórias a partir dos lugares santificados por terem sido palco da famigerada história da Paixão de Cristo. Ogier d'Anglure anuncia Jerusalém como alvo, mas destaca o mosteiro de Santa Catarina, no sopé do Monte Sinai, como um alvo de igual valor,; e Ghillebert de Lannoy, antes de dizer os outros diversos lugares que visitou, como Constantinopla, Chipre, Cairo, entre outros, declara que foi "a Jerusalém, e ao redor, a todos os lugares santos onde os peregrinos costumam ir $^{\prime \prime}{ }^{43}$ Qualquer deles, pois, deixa explícito que se conduz por práticas e relatos anteriores, o que garantia que não se perdesse "o caminho certo", como diz Mandeville. ${ }^{44}$

Mas diferentemente de Mandeville, que preenche sua narrativa com histórias profanas não menos correntes nos relatos do tempo - envolvendo personagens como o Grande Cã de Catai ou o célebre imperador cristão, o preste João, ou Maomé-, histórias que conferem interesse aos lugares por onde

39 ZUMTHOR, 1993, p. 288.

${ }^{40}$ GRABOÏS, 1998, p. 197.

${ }^{41}$ NOMPAR DE CAUMONT, 1858, p. 3.

${ }^{42}$ OGIER D'ANGLURE, 1878, p. 1.

${ }^{43}$ GHILLEBERT LANNOY, 1878, p. 11.

${ }^{44}$ JEAN DE MANDEVILLE, 2007, p. 37. 
supostamente teria passado, os nobres aventureiros apresentam os lugares santos de Jerusalém e os lugares do caminho e dos arredores com marcada monotonia, e as matérias tratadas são classificadas em função do itinerário percorrido. ${ }^{45}$ Assim, se a ilha de Lango em Nompar de Caumont é apenas citada como bem povoada e rica em bens, ${ }^{46}$ em Mandeville, é lembrada a lenda que faz dela um curioso interposto: a história da filha de Hipócrates que, de "formosa donzela que era, foi transformada em dragão por obra de uma deusa chamada Diana" e que aguarda o beijo de um corajoso cavaleiro para que sua forma venha a ser revertida à beleza original. Mandeville, portanto, mescla sua atenção ao itinerário com histórias que o tornam sedutor, mas os outros cavaleiros peregrinos não demonstram igual veia literária, ainda que incluam algumas breves lendas contadas pelos seus guias. ${ }^{47}$ Nompar de Caumont prende-se à precisão dos deslocamentos, Ogier d'Anglure, às conhecidas histórias bíblicas, Ghillebert de Lannoy, optando por uma espécie de tabela descritiva, aponta seu itinerário e o ilustra com histórias como a da ressurreição de Lázaro, a dos rogos de Ló para que Deus poupasse Segor ${ }^{48}$ de seu castigo ou a de São Marcos martirizado. Vemos, assim, nos relatos, referências bíblicas mais ou menos recorrentes de cidades como Rama, Belém, Jaffa, Jericó, Sodoma, Segor, Betsaida, Babilônia, entre tantas outras, e a lugares como o Vale de Josafá, onde, lembram os viajantes, a escritura diz que acontecerá o Juízo Final; ${ }^{49}$ ou o

45 ZUMTHOR, 1993, p. 288.

46 NOMPAR DE CAUMONT, 1858, p. 84

47 GRABOÏS, 1998, p. 197.

48 História também lembrada por: NOMPAR DE CAUMONT, 1858, p. 74.

49 OGIER D'ANGLURE, 1878, p. 16. 
Monte Calvário, onde Jesus foi crucificado; ${ }^{50}$ ou o Jardim Getsêmani, onde Nosso Senhor foi beijado por Judas quando os judeus o prenderam. ${ }^{51}$

Provavelmente presos às histórias que conferiam dignidade moral aos seus deslocamentos, os cavaleiros aventureiros, mesmo que movidos por interesses não religiosos, rememoraram as mesmas passagens referentes aos lugares do seu itinerário, mas Ghillebert de Lannoy vai um pouco além, descrevendo mais minuciosamente as condições das cidades e dos portos do Egito e da Síria, bem como alguns hábitos e costumes notáveis. ${ }^{52}$ Denuncia, assim, seus ímpetos exploradores. Nenhum dos viajantes referidos, a propósito, restringe-se a Jerusalém. Nompar de Caumont, por exemplo, ocupa-se das ilhas gregas, da Turquia, do reino da Cecília e de outros lugares, e suas peregrinações estendem-se igualmente a Santiago de Compostela. ${ }^{53}$ Mas ao contrário das saborosas histórias de Mandeville, temos aqui apenas o predomínio dos roteiros e das indicações das distâncias.

Assim, apesar de ser possível encontrar certas especificidades de uma ou outra história que caracteriza as cidades, a rememoração dos peregrinos do final da Idade Média dependeu do uso que fizeram de um arcabouço vocabular relativamente restrito: de um lado, nomes de cidades, igrejas, rios, portos, personagens bíblicas; de outro lado, indicações úteis a qualquer viajante, como distâncias, condições de deslocamento, perigos, dificuldades, benefícios encontrados. Significou também fazer uso de um pouco menos restrito conjunto de referências aceitas como

${ }^{50}$ GHILLEBERT LANNOY, 1878, p. 74.

${ }^{51}$ OGIER D'ANGLURE, 1878, p. 17

${ }^{52}$ Como os escravos do sultão da Babilônia. GHILLEBERT LANNOY, 1878, p. 117-119.

${ }^{53}$ Para um melhor conhecimento das rotas, ver: ROUX, 1985, p. 87-105. 
certas e verificadas: histórias bíblicas, legendas, referências à grandeza de certos reinos orientais, descrição de hábitos "invertidos" de certos povos não cristãos encontrados pelo caminho - como as mães que "choram quando nascem seus filhos, e ficam felizes quando morrem", 54 numa ilha nas proximidades do rio Ganges. Esse universo de referências escritas ou orais de outros viajantes tinha de tal maneira invadido as formas de conceber e efetivar as viagens santas que seria vão tentar separar o que viram ou leram homens como João de Pian del Carpine, Guilherme de Rubruc, João de Montecorvino, Riccoldo de Monte Croce, Symon Semeonis, Ludholf Sudhein, Jordan Catala de Sévérac, Ogier d'Anglure, Nompar de Caumont, Ghillebert de Lannoy, e menos ainda Jean de Mandeville, pois cada um desses e outros, com seus objetivos variados, convenceram seus leitores de que suas lembranças eram de percursos efetivos e de finalidades religiosas sinceras, embora não tenham perdido de vista sobretudo os vestígios escritos que encontraram por caminhos menos concretos, mas não menos reais.

Os poucos exemplos aqui fixados permitem-nos, pois, ilustrar o quanto esses viajantes queriam que suas recordações de viagem soassem convincentes. Apesar de limitados, são, porém, suficientes para indicar como a memória que fixaram transitou entre o compromisso de seduzir e estimular outros cristãos para a missão de expansão da fé católica e o encargo de dar forma a um mundo do além-mar (Mediterrâneo, Egeu, Negro, Vermelho), ou melhor, fora dos limites da civilização ocidental, ${ }^{55}$ há muito imaginado e, na altura das missões - a partir do XIII -, mais frequentado.

\footnotetext{
${ }^{54}$ JEAN DE MANDEVILLE, 2007, p. 238.

${ }^{55}$ GRABOÏS, 1998, p. 13.
} 


\section{Referências Bibliográficas}

\section{Fontes}

CATALA SÉVÉRAC. Les Mirabilia descripta. In : GADRAT, C. Une image de l'orient au XIVe siècle. Les Mirabilia descripta de Jordan Catala de Sévérac. Paris: École de Chartes, 2005.

CLARAVAL, Bernardo de. Sermão sobre o conhecimento e a ignorância. LAUAND, Luiz Jean (org.). Cultura e Educação na Idade Média. São Paulo: Martins Fontes, 1998.

GHILLEBERT LANNOY. Oeuvres de Ghillebert de Lannoy: voyages, diplomate et moraliste. Recueillies et publiées par Ch. Potvin, avec notes géographiques et une carte par J. C. Houzeau. Louvain: Imprimière de P. et Lefever, 1878.

GUILHERME DE RUBRUC. Itinerário. In: In: Crônicas de viagem: Franciscanos no extremo oriente antes de Marco Polo (1245-1330) / João de Pian del Carpine; et al. Trad. intr. e notas de Ildefonso Silveira e Ary E. Pintarelli. Porto Alegre/Bragança Paulista: EDIPUCRS/EDUSF, 2005.

JOÃO DE MONTECORVINO. Cartas. In: Crônicas de viagem: Franciscanos no extremo oriente antes de Marco Polo (1245-1330) / João de Pian del Carpine; et al. Trad. intr. e notas de Ildefonso Silveira e Ary E. Pintarelli. Porto Alegre/Bragança Paulista: EDIPUCRS/EDUSF, 2005.

JOÃO DE PIAN DEI CARPINE. História dos Mongóis. In: Crônicas de viagem: Franciscanos no extremo oriente antes de Marco Polo (1245-1330) / João de Pian del Carpine; et al. Trad. intr. e notas de Ildefonso Silveira e Ary E. Pintarelli. Porto Alegre/Bragança Paulista: EDIPUCRS/EDUSF, 2005.

MONTE CROCE, Riccoldo. Pérégrination en Terre Sainte et au Proche Orient. Texte latin et traduction par René Kappler. Paris: Honeré Champion Éditeur, 1997. 
NOMPAR DE CAUMONT. Voyaige d'oultremer en Jhérusalem par le Seigneur de Caumont l'an 1418. Publié pour la première foi d'après le manuscrit du Musée britannique par le Marquis de La Grange. Paris: A. Aubry, 1858.

ODORICO DE PORDENONE. Relatório. In: Crônicas de viagem: Franciscanos no extremo oriente antes de Marco Polo (1245-1330) / João de Pian del Carpine; et al. Trad. intr. e notas de Ildefonso Silveira e Ary E. Pintarelli. Porto Alegre/Bragança Paulista: EDIPUCRS/EDUSF, 2005.

OGIER D'ANGLURE. Le Saint Voyage de Jherusalem. Publié par François Bonnardot e Auguste Longnon. Paris: Libraire de Firmin Didot et Cie, 1878.

SUDHEIN, Ludolph de. Le Chemin de la Terre sainte. In: RÉGNIERBOHLER, Danielle (dir.). Croisades et Pèlerinages. Paris: Robert Lafond, 1997.

TOMÁS DE AQUINO. Suma Teológica. Vol. 7. São Paulo: Edições Loyola, 2002.

Viagens de Jean de Mandeville. Tradução, introdução e notas Susani Silveira Lemos França. Bauru: EDUSC, 2007.

\section{Estudos}

CHAREYRON, N. Globe-Trotters au Moyen Âge. Paris: Imago, 2004 CHAREYRON, N. Les Pélerins de Jérusalem au Moyen Âge. Paris: Imago, 2000.

COLEMAN, Janet. Ancient and medieval memories. Studies in the reconstruction of the past. New York: Cambridge University Press, 1992.

GILSON, Étienne. L'esprit de la philosophie médiéval. Paris: Librairie Philosophique J. Vrin, 1989.

GRABOÏS, A. Le pèlerin occidental en Terre Sainte au Moyen Âge. Paris: Bruxelles: De Boeck \& Larcier, 1998. 
HOOYKAAS, R. O Humanismo e os Descobrimentos na Ciência e nas Letras Portuguesas do Século XVI. Lisboa: Gradiva, 1983.

KAPPLER, R. Introduction. In: MONTE CROCE, Riccoldo. Pérégrination en Terre Sainte et au Proche Orient. Paris: Honoré Champion, 1997.

RÉGNIER-BOHLER, Danielle (dir.). Croisades et Pèlerinages. Récits, Chroniques et Voyages en Terre Sainte XIIe-XVIe Siècle. Paris: Robert Lafond, 1997.

ROUX, J. P. Les explorateurs au Moyen Age. Paris: Fayard, 1985.

SIGAL, P-A. Les marcheurs de Dieu. Pèlerinages et pèlerins au Moyen Age. Paris: Armand Colin, 1974.

VAZ, Henrique C. de Lima. Antropologia Filosófica. São Paulo: Loyola, 1991.

WOLFZETTEL, F. Le discours du voyageur. Paris: Presses universitaires de France, 1996.

ZUMTHOR, P., La medida del mundo: representación del espacio en la Edad Media, Madrid, Ediciones Catedra, 1993.

\section{Resumo}

As reflexões sobre a relação entre memória e esquecimento ganharam força entre os teóricos de diversas áreas nas últimas décadas e abriram espaço para as interrogações sobre o que moveu as escolhas do que deveria ser lembrado pelos homens de determinado tempo, já que tais lembranças ajudaram a definir os próprios mundos partilhados. O presente estudo tem como alvo questionar especificamente o que os viajantes cristãos medievais dos séculos XIII, XIV e XV quiseram lembrar e julgaram que era importante ser lembrado sobre as terras do oriente que tiveram aos poucos de dar a conhecer aos seus conterrâneos. 


\section{Abstract}

The reflections about the relationship between memory and forgetfulness have engaged the thinkers in the last decades and have enlarged the space for questions about what influenced the choices that should be remembered by men of a certain time, such that memories helped to define their own shared worlds. The object of the study is to question what travellers from 13th, 14th, 15th have wanted to remember and what they thought that were important to be reminded of the East's lands that had got gradually to known to their own countrymen. 